\title{
O corpo ao pé da letra: 0 sintoma entre o saber e o gozo
}

\section{The body to the letter: The symptom between knowledge and jouissance}

\section{El cuerpo al pie de la letra: El síntoma entre el saber y el goce}

\section{J oão Pedro Gomes Previdello*}

Universidade Estadual de Londrina - UEL, Londrina, Paraná, Brasil

\author{
I sadora Nicastro Salvador** \\ Universidade Estadual de Londrina - UEL, Londrina, Paraná, Brasil
}

Claudia Maria de Sousa Palma***

Universidade Estadual de Londrina - UEL, Londrina, Paraná, Brasil

\begin{abstract}
RESUMO
O artigo se propõe a analisar a especificidade do conceito de corpo, a partir da pulsão e da formação sintomática, a fim de refletir sobre a diferença no tratamento das configurações clínicas que escapam à construção simbólica. Essas organizações, ao prescindirem dos mecanismos psíquicos ordenados pelo recalque e pelo trabalho inconsciente de condensação e deslocamento, desnudam um corpo malvestido pelo simbólico, portanto, com importantes entraves ao endereçamento e à inclusão da alteridade. Como consequência, o sintoma não se encadeia pela via da associação livre, nem se orienta pela busca de algo no outro. Aparece enquanto real no corpo, atrelando-se ao caráter pulsional da compulsão à repetição. Assim, destacamos a prevalência de um arranjo em que o objeto a predomina como letra, resto, cuja função está em representar um sujeito analfabeto, no sentido de desavisado do que produz em seu corpo. Para o manejo clínico, o analista é, então, convocado a um outro lugar, diferente do ocupado no tratamento com os sintomas neuróticos. Trata-se de uma clínica do ato, orientada a um remanejamento de letras a realizar a necessária demarcação nesse gozo que irrompe no corpo.
\end{abstract}

Palavras-chave: psicanálise lacaniana, corpo em psicanálise, letra.

\section{ABSTRACT}

The article proposes to analyse the specificity of the concept of body, from drive and symptomatic formation, in order to reflect upon the difference in treatment of the clinic configurations that escape the symbolic construction. These organizations, by disregarding the psychic mechanisms ordered by repression and the unconscious work of condensation and displacement, disrobe a body barely dressed by symbolic, therefore, with important issues to address and include the otherness. As a consequence, the symptom is not chained by the free association mecanism, nor guided itself by the search of 
something in the other. Appears as real in the body, tying to the drive's compulsion trait of repetition. Therefore, we emphasize the prevalence of an arrangement in which the object a predominates as a letter, rest, whose function is to represent an illiterate subject, in the sense of being unaware of what is produced in its own body. For the clinic management, the analyst is summoned to another place, different from the occupied in the treatment of neurotic symptoms. It is a clinic of the act, oriented to a re-arrangement of letters to realize the required demarcation in that jouissance that erupts in the body.

Keywords: lacanian psychoanalysis, body in psychoanalysis, letter.

\section{RESUMEN}

El artículo propone analizar a especificidad del concepto del cuerpo a partir de la pulsión y la formación sintomática. Esto con el objetivo de reflejar la diferencia en el tratamiento de las configuraciones clínicas que escapan de la construcción simbólica. Estas organizaciones, al prescindir de los mecanismos psíquicos ordenados por la represión, y por el trabajo inconsciente de condensación y desplazamiento, desnudan un cuerpo mal vestido por lo simbólico, es decir, con importantes obstáculos en el direccionamiento y la inclusión de la alteridad. Como consecuencia, el síntoma no se enlaza por la vía de la asociación libre ni se orienta por la búsqueda de algo en el otro. Este aparece mientras es real en el cuerpo, atándose al carácter pulsional de la compulsión de repetición. De esa manera, destacamos la prevalencia de un acuerdo, en el que el objeto a predomina como letra, resto, cuya función está en representar a un sujeto analfabeto, en el sentido desprevenido de lo que se produce en su cuerpo. Para el manejo clínico, el analista es, entonces, convocado a otro lugar, diferente al que ocupó para el tratamiento con los síntomas neuróticos. Por lo tanto, se trata de un estudio del acto clínico orientada a una reorganización de letras para realizar la necesaria demarcación en ese goce que interrumpe en el cuerpo.

Palabras-claves: psicoanálisis lacaniana, cuerpo en psicoanálisis, letra.

Freud (1996b) fundou a psicanálise graças à particular narrativa das chamadas mulheres histéricas, mulheres que estabeleciam estranhas relações com seus corpos, relações essas que não se submetiam ao esperado pela própria Medicina, como nos casos de cegueiras ou paralisias parciais em que os devidos substratos fisiológicos faltavam. Com Freud, o sintoma histérico encontrou lugar peculiar e exclusivo, não mais causado por um útero, como acreditava-se na antiguidade, mas, sim, por um campo vivencial que tanto pode incidir nas condições fisiológicas como operar à parte delas (Freud, 1996b).

Assim, cabe não mais silenciar esse campo vivencial, considerado impróprio e estranho à abordagem do corpo biológico, mas, ao contrário, convidar a uma narrativa que inclua as experiências vivenciadas com o corpo, fazendo emergir um corpo historicizado, em que o tratamento à história produz o silenciamento nas expressões fisiológicas. Dessa maneira, a psicanálise começa a existir como escuta de um sujeito com um corpo que assume um sentido não restrito à fisiologia. Esse corpo revela uma significação muito 
particular, assentada nas vivências do sujeito; portanto, sem um sentido prévio evidente como se encontra no corpo estudado pela Medicina e pela Biologia, corpo-signo, ou seja, sinal a ser lido a partir de um sentido universal. Como destaca Fernandes:

Enquanto o corpo biológico obedece às leis da distribuição anatômica dos órgãos e dos sistemas funcionais, constituindo um todo em funcionamento, isto é, um organismo, o corpo psicanalítico obedece às leis do desejo inconsciente, constituindo um todo em funcionamento coerente com a história do sujeito. (Fernandes, 2003, p. 2)

Esse funcionamento corporal, condizente com a história do sujeito, diz de uma incidência e uma satisfação em um nível que Freud nomeia como pulsional. Dessa maneira, demonstra-se a relevância em se diferenciar da incidência e da satisfação instintual na sua expressão estritamente fisiológica.

Para localizar a pulsão, Freud (1996b, p. 127) estabelece um lugar de borda, circunscrevendo-a no limite entre o mental e o somático. De acordo com ele, “[...] um 'instinto' [pulsão] nos aparecerá como sendo um conceito situado na fronteira entre o mental e o somático, [...] [itálico nosso]". É uma definição importante para o trabalho que vamos aqui desenvolver, pois, mesmo ainda sob um paradigma biológico, Freud (1996b) percebe que a pulsão está para além de sua fonte biológica. Para além do que já implicava em uma complexidade que chamava a atenção de Freud, especialmente quando afirma que "de todas as partes que gradualmente se desenvolveram na teoria psicanalítica, a teoria dos instintos [pulsão] foi a que tateou mais penosamente o seu caminho [itálico nosso]" (Freud, 2011, p. 62).

Lacan também acentua essa perspectiva:

A pulsão, propriamente dita, é algo muito complexo, como vocês puderam ouvir da última vez, para aquele que a aborda de maneira aplicada tentando compreender o que Freud articula sobre ela. Não é redutível à complexidade da tendência entendida em seu sentido mais amplo, no sentido do energético. (Lacan, 2008, p. 251)

Essa complexidade oferece à pulsão uma importância teórico-clínica para a localização do psíquico na sua diferença ao aparato estritamente biológico. Assim, o campo pulsional perpassa a estrutura conceitual da psicanálise, ou seja, o recalque, a sexualidade, o desejo, a constituição do aparelho psíquico e as formações sintomáticas respondem aos desdobramentos pulsionais no viver de cada sujeito. No que tange ao presente estudo, o interesse é a abordagem teórica da satisfação pulsional na sua relação com o 
sintoma e o corpo, campo específico à psicanálise na sua compreensão do corpo para além da biologia.

\section{O Corpo Pulsional}

De acordo com Freud (1996b), a finalidade da pulsão é sempre sua satisfação. Dessa maneira, a partir de uma fonte biologicamente constituída, há uma pressão à satisfação que se efetiva no encontro com um objeto, o qual se constitui como alvo (Freud, 1996b, p. 127). Ou seja, uma pressão no aparelho psíquico que solicita descarga como via à satisfação, através de alguma diminuição da pressão, porque a eliminação é impossível. Isso se deve ao fato de a pulsão tratar de uma força sempre constante, cuja fonte é necessariamente interna, atributo essencial à sua diferença da pressão no campo biológico, cuja fonte é externa e momentânea (Freud, 1996b, p. 124).

Há, então, na vertente pulsional, uma emergência de um estímulo interno a ser descarregado a partir do corpo, pois a pulsão apresentase, de acordo com Freud, "como uma medida de exigência feita à mente no sentido de trabalhar em consequência de sua ligação com o corpo". (Freud, 1996b, p. 127). Com efeito, o trabalho psíquico que liga pulsão e corpo biológico é o que faz um corpo erogeneizado, corpo marcado pelos cuidados físicos de um outro que inscreve afeto, afetando o corpo para além do aplacamento fisiológico necessário à sobrevivência do humano. Ou seja, essa necessidade do outrocuidador impõe a entrada da carne nas vias do sentido ofertado pelo outro (Outro). Assim o sujeito ingressa no campo da linguagem, incitado a uma escolha forçada à via do sentido que recolhe do Outro como meio de sobrevivência, tomando o lugar de dependência a um Outro para se constituir humano. De acordo com Fernandes (2003, p. 9): "Isso equivale a dizer que é o investimento libidinal no corpo da criança, realizado por esse outro maternal, que ao torná-lo erógeno, Ihe permite acesso à simbolização".

A escolha forçada pela vida determina uma perda de si em função de uma vida a se constituir a partir do Outro e um consequente trabalho psíquico de regulação do campo da satisfação, perdida na sua plenitude, mas sempre buscada a partir das tentativas de recuperação. Nessa via, a erogenização com Freud ou com Lacan, a significantização do corpo procura contornar esse decepamento originário de uma parte de si mesmo. Bairrão (2003, p. 43) sublinha, com Lacan (2003), a importância dessa estruturação: "Lacan claramente vai identificar o corpo com o lugar concreto em que a estrutura é. Precisamente, vai fazer coincidir o corpo com a borda (real) do espaço em que os elementos da estrutura topologicamente calculáveis, os significantes, se inscrevem". 
A partir desta concepção, entendemos que o corpo significantizado tem como função dar consistência imaginário-simbólica ao real perdido do corpo, possibilitando uma ordenação que oferece a experiência de um corpo inteiro a um corpo inicialmente desordenado, despedaçado como se nomeia no tempo inicial do vivente. O corpo para além da fisiologia é, ao mesmo tempo, fonte para as necessidades de autopreservação e para as necessidades de satisfação pulsional cuja finalidade não é a reprodução. Dessa maneira, o corpo se enlaça ao sintoma como via de satisfação, tecendo amarrações que extrapolam a relação causa-resultado de ordenação fisiológica, estabelecida tão eficazmente pela ciência empírica no trato com o corpo.

\section{Corpo e Sintoma Psíquico ou Sobre a Satisfação Parcial}

A propriedade do corpo libidinal leva Freud ao conceito de um narcisismo que inclui a libido sexual também orientada ao eu (Freud, 1996a). Ou seja, o eu é também um objeto investido libidinalmente.

Pesquisas recentes dirigiram nossa atenção para um estádio do desenvolvimento da libido, entre o auto-erotismo e o amor objetal. Este estádio recebeu o nome de narcisismo. O que acontece é o seguinte: chega uma ocasião, no desenvolvimento do indivíduo, em que ele reúne seus instintos sexuais (que até aqui haviam estado empenhados em atividades auto-eróticas), a fim de conseguir um objeto amoroso e começa por tomar a si próprio, seu próprio corpo, como objeto amoroso, sendo apenas subsequente que passa daí para a escolha de alguma outra pessoa que não ele mesmo, como objeto. (Freud, 1996f, p. 68)

Assim, esse investimento no próprio corpo, que se articula com a definição freudiana do eu como antes de tudo corporal (Freud, 1980, p. 40), gera diminuição da tensão, estabelecendo um percurso de descarga que pode ser predominante ou mesmo fixo no aparelho psíquico, sem a orientação a um objeto externo.

O sintoma histérico, dessa maneira, porta uma satisfação pulsional, pois o corpo assume um lugar não subsumido estritamente ao biológico. Freud (1996d) observa uma relação entre a história da histérica e seu corpo com uma in-satisfação necessária e não controlada pela fisiologia ou pela racionalidade. Dessa forma, Freud recolhe uma narrativa de um corpo que representa algo absolutamente desconhecido pelo sujeito, sendo, portanto, o sintoma histérico a prova de que há algo para além (ou aquém) da consciência. Para tanto, Freud retira a explicação causal do campo 
universal biológico, que serve ao entendimento do funcionamento do corpo físico, revelando uma narrativa causal singular que se constrói a partir de experiências afetivas anteriores vivenciadas no corpo, porém contidas nas suas possibilidades de descarga. Tal acontecimento convoca um trabalho que transcorre aquém do campo da racionalidade da consciência e das incidências biológicas, trabalho esse que orienta o interesse de Freud no tratamento desse corpo específico que suas pacientes histéricas revelavam.

Este corpo com sua narrativa particular é palco para o encontro com uma satisfação que se estrutura a partir da articulação com a linguagem, isto é, com o Outro. Desse modo, corpo marcado pelo inconsciente a partir de um trabalho psíquico orientado pelo princípio do prazer na direção de uma satisfação parcial, pois limitada pelas possibilidades simbólicas.

Ou seja, a pulsão vinculada ao simbólico liga-se ao Outro, sendo então marcada pelo vestígio de um significante, como assinala Lacan (1995, p. 47): “[...] tudo o que se apresenta na vontade, a tendência, a libido do sujeito é sempre marcada pelo vestígio de um significante". Pois os significantes são a marca, os vestígios do pedaço de corpo perdido para a assunção de um sujeito. 0 significante, com sua propriedade de sempre se remeter a outro significante, condensa (metaforiza) e desloca (metonimiza) os fragmentos significantizados que, servindo à operação de sentido, instituem um corpo "subjetivo" em que o sintoma, submetido à ordem significante, é estruturado como um enigma-mensagem, dirigido ao Outro e possível de ser decifrado. Nesse entendimento, quando há um sintoma psíquico, há um trabalho que inclui uma libidinização do corpo, isto é, um encadeamento da pulsão ao Outro.

Essa é a perspectiva que se alinha e é acrescida à clínica da neurose estabelecida por Freud. Para os nossos interesses, temos também com Freud as consequências de um investimento corporal que prescinde de uma relação objetal. São os quadros denominados neuroses de angústia os quais permitem reconhecer, a partir dessa diferença clínica, um funcionamento no núcleo do sintoma resistente ao tratamento, uma satisfação que não busca uma ligação objetal como meio à descarga, mas também não investe o próprio corpo como ocorre com o narcisismo primário, enfim, um sintoma que não produz historicidade.

Freud detectara essa condição com a resistência ao trabalho clínico dos neuróticos que apresentavam uma neurose de angústia, destacando sobre essa: "a angústia da neurose de angústia não era continuada, relembrada, histérica" (Freud, 1996e, p. 241). Freud observara que na neurose de angústia há uma tensão física em que, não havendo conexões psíquicas suficientes para lidar com a tensão, esta é transformada em angústia, afeto não nomeado, mas reconhecido no corpo. Portanto, localiza configurações em que há 
uma insuficiência psíquica, ou seja, de ligação, para lidar com uma tensão ao nível do corpo (Freud, 1986).

Essa descrição freudiana orienta o interesse de nosso tema de estudo a partir de duas interrogações: 1 . O que acontece quando não se pode efetivamente contar com o alcance que uma história oferece à ordenação do mal-estar de um sujeito via sintoma psíquico? 2. Como abordar a terapêutica quando a pulsão faz sua descarga direta no corpo, de modo distinto das sintomatologias clássicas estudadas por Freud, cuja característica fundamental é a mediação da linguagem e do princípio do prazer a dirigir as condições de descarga pulsional via sintoma?

Sobre esta relação entre pulsão e corpo, Assoun, citado por De Aguiar, esclarece:

A pulsão não exerce seu trabalho destrutivo em nenhum outro lugar a não ser em seu cercado orgânico (o organismo). [...] Mas o lugar mesmo do desintricamento pulsional seria a divisão do orgânico com ele mesmo: nós não podemos achar uma forma mais radical de morbidez física inconsciente. (Assoun, 1997 como citado em De Aguiar, 2007, p. 50)

O autor, expondo o próprio caráter destrutivo da pulsão em seu desintricamento, que aqui articulamos com a formulação da descarga direta, indica o caráter de morbidez que tal operação constitui, sinalizando que se trata do campo da pulsão de morte.

\section{Corpo e Sintoma ou a Busca Pela Satisfação Perdida}

Esse tema pode ser desenvolvido a partir do que Lacan esclarece sobre o esquema simbólico, especialmente quando sublinha que há outra coisa não marcada pelo significante:

Este esquema comporta que o que é significante de alguma coisa pode se tornar a qualquer momento significante de outra coisa, e que tudo o que se apresenta na vontade, a tendência, a libido do sujeito é sempre marcado pelo vestígio de um significante - o que não exclui que talvez haja outra coisa na pulsão ou na vontade, algo que não é de modo algum marcado pela impressão do significante. (Lacan, 1995, p. 47)

Um ponto limite para a mediação da linguagem, ou o núcleo-duro do sintoma simbólico. Nesta descarga direta no corpo, há na pulsão, como descrito por Penna (2003), um imperativo que não responde ao princípio do prazer: 
A pulsão, em sua exigência incessante, promove o trabalho significante do inconsciente e, ao mesmo tempo, aponta para o limite do que aí se constitui como saber. É esse limite que vem franquear a noção de pulsão de morte, um conceito que, obtido da compulsão à repetição, abrange o conjunto dos fatores que fazem obstáculo aos remanejamentos inconscientes da metáfora e da metonímia, regidos pelo princípio do prazer. 0 conceito de pulsão de morte é indicativo de uma zona silenciosa que faz limite às possibilidades infinitas da rememoração e, por conseguinte, aponta para o limite da dimensão clínica da interpretação, solicitando uma outra operação, a "construção" em análise. (Penna, 2003, p. 66)

Dessa forma, instaura-se um campo clínico outro, orientado de forma pregnante pela compulsão à repetição de algo não simbolizado, nem simbolizável. Portanto, sintomas em que a incidência simbólica falha como direção predominante ao tratamento e a descarga pulsional não cede ao princípio do prazer.

Freud, em Além do Princípio de Prazer (1996d), constatara uma pressão no sintoma não articulada a uma ideia a ser rememorada, mas a um movimento constante e sem sentido, uma compulsão incapaz de gerar significações, apresentando-se como pura insistência de atos repetidos que visam um sem sentido, isto é, mais precisamente, o encontro com o objeto perdido, em que a economia psíquica do princípio do prazer não reina. Portanto, temos na economia psíquica, um lugar de independência ao circuito do prazer, lugar da pulsão de morte, apreendida como não sexualizada, impossível de decifração, desagregadora, não ligada.

Essa via não sexualizada, para Lacan, contempla o núcleo pulsional em que, segundo o autor, "toda pulsão é virtualmente pulsão de morte." (Lacan, 1998c, p. 863). Como desdobramento, no mesmo trabalho, Lacan esclarece que as pulsões sexuais em Freud são apenas pulsões parciais, ou seja, são apenas uma parte da pulsão que faz enlace, ligação, pois a pulsão propriamente dita é pulsão de morte. Desse modo, articulando as perspectivas de Freud e Lacan, o campo da pulsão de morte se faz presente apontando para uma busca de satisfação impossível, pela via de algo que Lacan denominou gozo, uma satisfação permeada pelo excesso que o impossível convoca produzindo, ao mesmo tempo, prazer e dor.

Queiroz (2012) afirma que "a dor, na concepção freudiana, está regida pelo princípio do prazer-desprazer. Se a noção de pulsão de morte deu a Freud a condição de enxergar além do princípio do prazer-desprazer, foi Lacan quem nomeou essa dor mais além do princípio do prazer-desprazer como gozo [...]". (Queiroz, 2012, p. 856). Logo, no sintoma, há uma pressão por uma satisfação não 
regida pelo princípio do prazer, mas no que está além dele, uma elevação tensional.

Nessa perspectiva, de acordo com Lacan (2008), “[...] o gozo se apresenta não pura e simplesmente como a satisfação de uma necessidade (besoin), mas como a satisfação de uma pulsão [...]" (Lacan, 2008, p. 251). Satisfação que excede, portanto, desarticulada do princípio do prazer e do campo protetivo simbólico expressos nas pulsões parciais. Por este motivo, no sintoma enquanto pura expressão de gozo, real, não se trata de uma necessidade ancorada em alguma utilidade, em que o corpo se apresenta como parceirosimbólico, articulado ao princípio do prazer; ao contrário, aqui, o corpo fica exposto ao caráter imperativo da pulsão, uma libra de carne.

De acordo com De Castro (2011, p. 1411): "Se abolir as palavras implicaria recorrer às próprias coisas para comunicar-se, é porque a palavra em si mesma implica a ausência, o cancelamento, a morte da coisa". Dessa forma, a palavra, ancorada pelo registro simbólico, entra no lugar de alguma coisa para que possa dar sentido ao vazio deixado pela coisa, na sua ausência. Quando a coisa está lá, por si só, não-mediada pelo simbólico, pela falta, ela fica exposta, vivificada, viva de ser. A palavra se inscreve na morte daquilo que estava no real, pois, agora, o corpo deixa de ser coisa alguma e adquire estatuto de alguma coisa pulsante.

Assim, a ausência adquire um estatuto fundamental ao encaminhamento de uma existência, simbólica, a orientar uma aproximação à coisa ausente. Ou seja, dizendo de outro modo, a pulsão na vertente de uma satisfação parcial. Lacan (1998a) desenvolve essa perspectiva quando aborda a função da negação no discurso: “[...] a morte nos traz a questão daquilo que nega 0 discurso, bem como de saber se é ela que introduz neste a negação. Pois a negatividade do discurso, na medida em que faz existir o que não está ali, remete-nos à questão de saber o que o não-ser, que se manifesta na ordem simbólica, deve à realidade da morte." (Lacan, 1998a, p. 381).

Se o sentido se manifesta na ordem simbólica pela falta da coisa, é porque a palavra mata o ser, a palavra existe na ausência do ser. Com efeito, neste sintoma carente das palavras, há um corpo exposto, escancarado. Segundo Dal-Cól, “[...] o gozo em reserva não está deslizando sob a cadeia significante, porém também não está fora, em explosão. Está no corpo, nem dentro, nem fora da cadeia, mas no limite. Não é nem enigmática para o sujeito, tampouco siderante. Só é!". (Dal-Cól, 2016, p. 113)

Desse modo, podemos dizer que o corpo não é apenas a morada do Outro, mas também lugar daquilo que escapa à representação, fazendo-se presença. Assim, estamos no campo da pulsão 
propriamente para Lacan, em que há sempre um excesso não abarcado pelo sentido. De acordo com Fernandes:

Se com a histeria Freud faz do corpo o lugar de uma simbolização, problematizando a relação entre psiconeuroses e as neuroses atuais, abre com isso caminho para pensarmos um corpo de transbordamento. Admitindo a possibilidade de que nem sempre o corpo biológico está vinculado a um sistema significante, abre-se igualmente a possibilidade de pensarmos 0 sintoma corporal como uma descarga, como um excesso, que, atravessando o aparelho psíquico, não se organiza necessariamente a partir da lógica da representação. (Fernandes, 2003, p. 3)

Portanto, falamos de dois corpos, não que existem em separado, mas que respondem a operações diferentes: um de caráter predominantemente simbólico e outro de um caráter real. Tais operações dizem de dois campos, o campo da linguagem e o campo do gozo.

No campo da linguagem e da relação edípica, a partir de Lacan (1998a), o S2, Nome-do-Pai, intervém no campo do Outro como a lei que ordena a incidência materna (S1), barrando o gozo desenfreado do lugar do A. Dessa forma, essa função é a responsável por regular o gozo, inscrevendo um furo em condições de fazer uma falta.

Nessa medida, demonstra como a criança se tornará sujeito a partir da operação da metáfora paterna e de seu mecanismo, o recalque originário, que se desenvolve com base numa substituição significante, na qual um significante novo tomará o lugar do significante originário do desejo da mãe que, recalcado em benefício do novo, vai se tornar inconsciente, o que significa que a criança renunciou ao seu objeto inaugural de desejo. (Ramirez, 2004, p. 92)

Nessa condição de renúncia do gozo pleno em prol de uma significação a partir de uma falta, há uma resposta a esta renúncia, que é traumática, aparecendo um sintoma simbolizado, passível de representação, pois o furo fez-se presente num tempo anterior, permitindo a inscrição de uma falta, a significação fálica, produzida pela intervenção do Nome-do-Pai no lugar do Outro materno. O resultado da operação é uma perda de gozo, em prol de um gozo fálico, parcial. Os vestígios dessa perda se dão na erogeneização de certas partes do corpo, fazendo-se um corpo fálico.

Por ser simbólica, é possível operar a função paterna como uma metáfora. Tornando-se significado de metáfora como um 
significante que vem no lugar de um outro significante, o nome-do-pai entra em substituição ao falo como objeto de desejo da mãe. (Ramirez, 2004, p. 92)

O Nome-do-Pai indica uma função simbólica, como esclarece Fink (2008, p. 78): “[...] o pai ou algum outro membro da família ou algum outro interesse da mãe pode desempenhar uma função muito específica: a de anular a unidade mãe-criança, criando um espaço ou uma lacuna essencial entre elas". Porém, o mesmo autor já destacara que apenas a instalação da função paterna não é o suficiente para que se produza uma cadeia significante:

É necessário dar um passo à frente para que aquilo que substitui ou ocupa o lugar do desejo do Outro materno passe a funcionar como um significante "plenamente desenvolvido" [...] A substituição subentendida pela metáfora paterna somente se torna possível pela linguagem e é, portanto, somente na medida em que um "segundo" significante, S2, for instalado (o Nome-do-Pai, no início, e depois mais amplamente o significante do desejo do Outro) que o desejo da mãe é retroativamente simbolizado ou transformado em um "primeiro" significante (S1). (Fink, 1998, p. 80)

Propomos então que o pai, em sua função, abriu uma lacuna que apenas diferencia a criança da mãe, como um traço de pura diferença, mantendo o desejo da mãe não simbolizado, ou seja, fora do estatuto significante e das operações de trânsito simbólico à pulsão. Logo, sendo apenas traço, essa abertura não é capaz de produzir um S1 no lugar do desejo da mãe, não sendo possível um espaço para existência como significante, e, por consequência, a possibilidade de uma metaforização com outro recurso de descarga.

Portanto, apenas um S1 incidindo como um traço, sem significância, que, de acordo com Dal-Cól (2016, p. 110), é uma "marca a céu aberto de um gozo ilegível". Assim, não houve intervenção no campo do Outro primordial a partir da operância do S2, permitindo em sua via de retorno a produção de um sentido à falta a partir da perda.

Sem essa operação na sua efetividade, instaura-se um S1 que faz marca no corpo. Nesse âmbito, a resposta sintomática é diferenciada, porque não há ligação entre S1 e S2, logo o resto esperado - a - não se estabelece fora da operação. O S1 ligado ao corpo - Um - captura o sujeito absorvendo o que deveria ficar fora, fazendo do mais-degozar- a -insígnia do sujeito. De acordo com Miller (1986, p. 37, tradução nossa): "desde este ponto de vista, em todo sou há uma remissão ao Outro. A captura do sujeito pelo unário, pelo Um, sempre deixa um resto, esse resto que é a, esse resto inefável. É importante 
não absorvê-lo ao unário, à insígnia, e manter essa insígnia distinta do mais-de-gozar [...]".

O sujeito, então, aparece puramente imerso em um campo de gozo, em que há uma satisfação pulsional excessivamente corporal, com a incidência imperativa do mais-de-gozar na função do unário. Esse S1 age enquanto Nome-do-Pai, no lugar do objeto que deveria estar em falta, orientando o circuito de satisfação fixado nesse ponto. Assim, traço que fixa.

Sem a ligação ao S2 a oferecer o estatuto de significante ao S1, a partir da queda do objeto, da falta necessária para que o significante ocupe o lugar do objeto, produzindo com seu corte a divisão, isto é, o sujeito barrado dessa satisfação, o que se instaura é um corpo voltado ao lado real, S1 signo, colado no corpo. Como resultado, temos a precarização do campo simbólico do inconsciente nas sintomatologias atuais, em que a perspectiva estrutural neurose/psicose/perversão - não será aqui problematizada, mas, sim, a vertente real que compõe toda estrutura na sua expressão sintomática quando predominante.

Nessa perspectiva, retomando um ponto que nos interessa, entre 0 campo do gozo, S1, e o campo da linguagem, S2, há algo que se perde, representado pela letra a. De acordo com Penna (2003), algo que jamais pode ser reencontrado, mas, que por ser perdido, deixa rastros os quais servem como coordenadas de satisfação. Nesse sentido, segundo ele:

Nesse momento originário e mítico, já se introduz o que podemos ler como sendo a divisão constitutiva do sujeito. Por um lado, algo do corpo, da vida que urge, exigindo uma satisfação e, por outro, a impossibilidade dessa satisfação plena e completa, na medida em que aos objetos do mundo faltará sempre um atributo que devolva essa satisfação total. (Penna, 2003, p. 51)

É nesta urgência de corpo que se instaura a segunda clínica de Lacan, em que, conforme Leite (2000, p. 176), "haveria então uma mudança da ênfase do entendimento do inconsciente de um "querer dizer", que seria o paradigma da primeira clínica, para um "querer gozar", paradigma da segunda clínica". Nesse paradigma, é tomar o corpo do sujeito para dar vazão ao gozo, ao real, o que não porta sentido. 0 sintoma se apresenta como uma satisfação de gozo, eis o que nomeamos como sintoma no campo imaginário/real, pois o corpo fazse de sintoma. Ou seja, não havendo acesso à via simbólica de operação com o resto via satisfação parcial, o corpo incorpora a função imaginária do objeto a, fazendo-se mais-de-gozar.

Neste corpo-carne, o trajeto, aqui, segue a via oposta à que Freud elaborou ao recolher a narrativa através do corpo das pacientes 
marcadas pela perda do objeto. O intuito do presente trabalho é o retorno ao corpo sem narrativa, ao corpo-resto, não incluída a significantização da perda do objeto.

\section{Configurações Clínicas Atuais: I ncidências da Letra}

Este corpo desarticulado de uma narrativa se apresenta nas chamadas sintomatologias atuais, como nas adicções, nos transtornos alimentares, nas automutilações, que são exemplos específicos de como o gozo pode predominar em sua função imperativa, não atravessado pela linguagem e seus desdobramentos psíquicos. Logo, um sintoma não mais portador de uma mensagem, mas veículo de um empuxo da pulsão presentificada no corpo-carne. Como esclarece Caroz:

[...] todos estes transtornos hipermodernos testemunham a elevação ao zênite de um gozo que não se reabsorve na estrutura. [...] Essa perda da medida testemunha quanto o falo perdeu seu vigor. Notemos que os nomes dados a essas comunidades de seres falantes (falasseres) hiper ou dis são tentativas de classificar os sujeitos, não a partir de suas construções simbólicas, mas a partir do gozo que os congrega. [...] (Caroz, 2013, p. 80)

Para abordar aquilo que é da ordem do gozo, Lacan nos apresenta a letra, esclarecendo que "a letra é o que escreve" (Lacan, 1985, p. 63). Nesse caso, já não diz mais respeito à relação com o significante, àquilo que se constrói pela via do simbólico, pois "a escrita, a letra, está no real, e o significante, no simbólico". (Lacan, 2009, p. 114).

Avançando no conceito, Lacan a situa como "uma rasura, um resto apagado que não tem relação nenhuma com o sentido, mas passa a armazenar um gozo, encarnando o que há de pulsional na língua" (Lacan, 1985, p. 63). Assim, a letra escreve algo que não se endereça à leitura, à produção de sentido, mas faz um escrito. De acordo com Zucchi (2014, p. 9-10), "não é texto, mas é escrita. Talvez como a tatuagem de muitos aqui: nada a compreender, apenas dizer...". Nessa perspectiva, o que se escreve, como via de descarga nos fenômenos que reconhecemos como psicopatológicos na atualidade, não o faz simbolicamente a partir das operações de metáfora e metonímia orientando-se, a descarga, num sintoma psíquico, mas, sim, via marca no corpo através de cortes, como a automutilação, ou das marcas ósseas da anorexia à imagem, que mostram como a pulsão de morte pode ter incidência direta no corpo real, satisfação estrita de gozo. 
A simbolização do corpo, de outra forma, circunscreve a vazão pulsional. Nela, o objeto a enquanto perdido, resto da operação de divisão, presentifica-se nas bordas corporais que contornam um vazio por onde a pulsão faz seu circuito: oral, anal e fálico. Entretanto, quando o corte falha e não se efetiva a incidência simbólica na orientação da pulsão, o objeto a, que não foi perdido, acopla-se ao sujeito e toma o corpo como escoadouro pulsional. Logo, o corpo é o objeto.

Nicolau e Guerra (2012) desenvolvem essa perspectiva em que o corpo toma lugar do objeto: "assim, o que entra em jogo na relação com o outro é o órgão, a imagem especular do próprio corpo. A relação se estabelece, portanto, no campo do auto-erotismo, onde não se distingue fonte de objeto" (Nicolau \& Guerra, 2012, p. 229). Quando a inscrição de uma borda simbólica não se efetiva, (de) limitando a experiência gozante a partir de um corpo sintomatizado pela incidência do Outro, temos um sintoma que transborda no próprio órgão, tomado como objeto.

Com efeito, um corpo sem bordas se orienta por uma marca que apenas indica um escoar de gozo, marca esta em que a e sujeito estão colados. O sujeito, então fixado, enraíza-se no silêncio pulsional que a ausência da efetividade significante impõe e, ao não ser capaz de operar com esse real pulsional, usa do próprio corpo para escoar aquilo de inapreensível, irrepresentável, criando um sintoma que não é da ordem do sentido, mas de uma vivificação do objeto a no corpo. Essa perspectiva se relaciona às produções acerca do fenômeno psicossomático, o qual tem sido utilizado como função exemplar para a diferença de um sintoma psíquico, sendo que destacamos a descarga direta no corpo de um sujeito-objeto, aproximando-se, portanto, metapsicologicamente, do interesse do presente trabalho. De acordo com Rinaldi, Nicolau e Pitanga (2013, p. 96): "se, para a medicina, as disfunções sem causa orgânica são diagnosticadas como doenças psicossomáticas, para a psicanálise impõe-se precisar a diferença entre sintoma e fenômeno psicossomático na direção da cura."

No entanto, o termo "fenômeno psicossomático" não nos parece adequado para designar o que é do nosso interesse. Desse modo, concordamos com a posição de De Aguiar (2007), que demonstra como o conceito de "fenômeno psicossomático" sofreu distintas concepções nos discursos médico, psicopatológico e da própria psicanálise. Nessa perspectiva, Assoun (1997) demonstra que:

Dever-se-ia ter considerado mais seriamente a «invectiva» de Freud: se o inconsciente fosse o «elo faltante» entre o psíquico e o somático? Assim sendo, seria preciso soldar os efeitos deste "inconsciente" em suas duas bordas e re-interrogar a metapsicologia ou o saber do inconsciente, quanto ao corpo, 
tanto o corpo quanto à metapsicologia. (Assoun, 1997, como citado em De Aguiar, 2007, p. 9)

Sendo assim, a própria metapsicologia freudiana já abarca o campo da ordem do somático quando problematiza o sintoma psíquico. Portanto, recorrer às novas nomenclaturas, como o uso do termo "fenômeno", não sustenta a problemática do presente estudo, interessada numa organização psíquica e não em alguma ruptura ou contingência que faz emergir um fenômeno como resposta a uma desorganização circunstancial e que pode não mais se apresentar.

Entretanto, a presença do acontecimento - fenômeno psicossomático - que desnuda um curto-circuito numa organização simbólica prévia, aproxima metapsicologicamente o nosso interesse da apreensão teórica dada ao fenômeno, enquanto um modo de descarga direta na inoperância do aparato simbólico. Essa perspectiva de entendimento é desenvolvida pela escola de Paris, em que se destacam Marty e M'Uzan (1994) e também em alguns trabalhos que versam sobre a insistência na descarga direta, como nas pesquisas de Santiago (2001) ao estudar as toxicomanias.

Nessa via, relacionando a estruturação do fenômeno psicossomático com o conceito de uma vivificação de objeto a no corpo, as formulações a respeito do fenômeno psicossomático apontam para o narcisismo presente, como destaca Dal-Cól:

No fenômeno psicossomático a referência ao narcisismo é fundamental, mas só o é na medida em que se considera o objeto como o próprio corpo. Nos investimentos denominados autoeróticos não se pode distinguir qual é a fonte e qual é o objeto, pois disso nada se sabe, mas se pode conceber que se trata de um investimento sobre o próprio órgão. (Dal-Cól, 2016, p. 36)

Objeto que encarna o real da pulsão e, nessa face não apreensível simbolicamente, o objeto a. Nessa vertente, Santiago (2001) indica a natureza de objeto da letra: "pode-se dizer que, nessa anulação do significado, a letra se aparta do símbolo em função de sua natureza de objeto". (Santiago, 2001, p. 38)

Em relação à constituição subjetiva, se a incidência de S2 é o que produziria o sujeito do significante nesse espaço entre os dois significantes, S1 e S2 (Lacan, 1998b, p. 187), na ausência do S2, o objeto a aparece colado a $\mathrm{S} 1$, produzindo uma espécie de sujeitoobjeto. Tem-se um sujeito, mas um sujeito que chamaremos de inletrado, pois, o prefixo "-in" na língua portuguesa refere-se a um estado de privação - privação do a separado, na sua função de símbolo -, mas também diz respeito ao movimento para dentro tomado por um corpo. Portanto, esse sujeito in-letrado está incapaz 
de um saber-fazer com a letra justamente por estar assujeitado a ela como corpo.

Não há um "sujeito letrado" que possa operar com essa marca, objeto a colado ao S1, incluindo-a no campo simbólico, S2, como escrita de uma ausência necessária à vida. Há um sujeito in-letrado, ou seja, completamente desavisado do que produz no próprio corpo como resposta a uma presença que deveria faltar. Entende-se, dessa forma, o porquê da inutilidade em tratar pela via simbólica tais sintomas do corpo real, pois a letra é sempre vazia de sentido. Como ressalta Nicolau e Guerra (2012, p. 233): “É precisamente o ilegível, o que não se dá a ler na letra, esse não-a-ler da letra que aponta para o gozo no fenômeno psicossomático".

Este não-a-ler da letra remete ao equívoco de James Joyce, de onde Lacan (2009, p. 106) parte com o jogo de palavras que evoca - letter e litter, carta e lixo: "[...] partida do equívoco com que Joyce - é de James Joyce que estou falando - desliza de a letter para litter, de uma carta/letra, traduzo, para um lixo". Esse ponto preciso que Lacan apreende com Joyce, é onde nos parece fazer entrada a estruturação do sintoma em abordagem no presente trabalho, e que tem, nesse deslizamento da letra, uma possível saída.

A letra, como já exposto, abarca o pulsional, o objeto a que também é uma letra, objeto do resto do ser como supracitado. Em sua face de litter, faz do corpo dejeto de objeto a, e na face de letter faz desse dejeto algo com uma destinação, e não mais perdido.

Eis a face da letra que permite a saída, aquela em que não mais toma o resto como lixo, mas do resto uma marca que, embora não seja um dizer, possui uma destinação de letter, fazendo com que não se encarne o pulsional pela via do lixo, da exterioridade com que essa marca se apresenta diante do sujeito. A destinação, como indica Vidal (2000, p. 25), "é destino que deve ser realizado, o término a ser efetuado. Esse destino é o sujeito, que, como efeito do inconsciente, não pode ser eliminado". Não é possível ensinar alguém a ser James J oyce, mas fazer a guinada do ser a uma espécie de lixeiro, é fazer desse resto um trabalho, do lixo enquanto chorume ao lixo reciclável. Fazer do corpo não um aterro sanitário, mas uma composteira.

O sujeito antes precisa delinear sua letra, para então a possibilidade de um traço simbólico entrar na cena. Sem tal delineamento, o sujeito, portador deste corpo que dá vazão ao sintoma real, escreve o seu lugar de falta, escreve, a partir da letra, o objeto a. O corpo ao ocupar esse lugar de objeto a escancara a falta, o rastro do ser. De acordo com Masagão (2008, p. 315): "ele cria em ato o objeto que se perde, que se destaca do corpo, mas que é parte do corpo, o objeto a, objeto parcial da pulsão".

Não se trata de construir um saber, mas retirar a letra como um lixo perdido no corpo. Não há o que se buscar no lixo, a letra, nessa via, fica perdida nesse corpo que é puro dejeto, mas localizando-a na face 
de letter produz-se essa destinação que permite ao sujeito se haver com esse gozo outrora perdido no corpo.

Essa letra que está exposta com o sintoma do corpo real permanece ilegível, mas condensa o gozo. A escrita é singular, mas a leitura demanda um Outro, um significante binário.

Há, então, a mudança de lugar da letra pela letra, apenas como marca de gozo, objeto a, para uma letra como estrutura base para uma relação de palavras para que algo se possa ler. Essa letra exposta no corpo, antes da análise, funciona como um hiato, objeto a, abrindo uma fenda, uma lacuna, como a fenda aberta nos pulsos pelo fio da navalha no sintoma, marcando essa não-continuidade de um corpo, um corpo dissonante.

Desse modo, conclui-se que a letra é a demarcação, corte entre o campo do gozo (real) e o campo do saber (simbólico). Ao ser relacionada com o litoral, por Lacan, entende-se que a letra, tanto como o litoral, que faz fenda entre o mar e a terra, é uma fenda entre o real e o simbólico. A consequência dessa fenda são furos, são buracos, cortes no corpo. Buracos mostrados, visíveis, fazendo-se aparecer.

Como indica Lacan (2009, p. 113), "Entre centro e ausência, entre saber e gozo, há litoral, que só vira literal quando, essa virada, vocês podem tomá-la, a mesma, a todo instante. É somente a partir daí que podem tomar-se pelo agente que a sustenta.". Portanto, é produzir a virada da escrita de uma rasura perdida à escrita autoral, é isso que a passagem do litoral ao literal evoca, de litter à letter, evocando assim o agente em sua destinação que o sustenta, ou seja, o sujeito condenado aos efeitos da linguagem, fazendo desse não mais um analfabeto, não mais o lixo de sua letra, mas agente de sua caligrafia própria, singular.

\section{Considerações Finais}

Nosso caminho partiu dos sintomas clássicos abordados por Freud, sintomas metaforizados e interpretáveis, para encontrar com os sofrimentos que não respondiam à simbolização histérica, como a neurose de angústia. Um sintoma que não tem nome, em que predomina a pulsão de morte e o corpo real. Para este, o tratamento pela via da historização já não produz efeito, pois não trata da ordem significante, mas do real pulsional.

Diante desta singularidade de um sintoma que faz marca, esburaca, mas não faz história, buscamos em Lacan aporte para circunscrever esta configuração sintomática e encontramos, na letra e no objeto a, um modo de enlace teórico e de percurso clínico a este em comparação ao que é identificado no tratamento aos fenômenos psicossomáticos. Este campo, por meio de uma urgência de corpo e 
uma escassez de fala, expõe a característica gozante e corpórea que o circunda, intimando a um percurso outro de trabalho analítico: uma clínica do ato que remaneje letras.

\section{Referências}

Bairrão, J. F. M. H. (2003). Corpo e inconsciente. Revista Olhar, 5(8), 40-48.

http://www.ufscar.br/ revistaolhar/pdf/olhar8/OLHAR8_3.pdf

Caroz, G. (2013). Depois do Édipo? O que quer dizer? Textos do VI ENAPOL. VI Encontro Americano de Psicanálise de Orientação Lacaniana. Falar com o Corpo. A Crise das Normas e a Agitação do Real, Buenos Aires, Argentina. Recuperado de http: //www.enapol.com/pt/template. php?file=Textos/Despuesdel-Edipo_Gil-Caroz.html

Dal-Cól, D. M. L. (2016). A escrita e o corpo em psicanálise e sua implicação nos fenômenos psicossomáticos (Tese de Doutorado). Instituto de Psicologia, Universidade Federal do Rio de Janeiro, Rio de Janeiro, RJ .

De Aguiar, A. L. (2007). O sintoma somático e a perspectiva de PaulLaurent Assoun: considerações metapsicológicas. (Dissertação de Mestrado). Universidade Federal do Ceará, Fortaleza, Brasil.

De Castro, J. C. L. (2011). A palavra é a morte da coisa: simbólico, gozo e pulsão de morte. Revista Mal-Estar e Subjetividade, 11(4), 1405-1420. Recuperado de http://pepsic.bvsalud.org/pdf/malestar/v11n4/05.pdf

Fernandes, M. H. (2003). Entre a alteridade e a ausência: o corpo em Freud e sua função na escuta do analista. Estados Gerais da Psicanálise: Segundo Encontro Mundial. Tema: A experiência psicanalítica e a cultura contemporânea (pp. 1-15). Recuperado de http://egp.dreamhosters.com/encontros/mundial_rj/download/ 3_Fernandes_116151003_port.pdf

Fink, B. (1998). O sujeito e o desejo do Outro. In B. Fink, O sujeito lacaniano: entre a linguagem e o gozo (pp. 71-92). Rio de Janeiro: Jorge Zahar.

Freud, S. (2011). O mal-estar na civilização (P. C. Souza, Trad.). São Paulo: Companhia das Letras.

Freud, S. (1996a). A história do movimento psicanalítico, artigos sobre a metapsicologia e outros trabalhos. In Edição standard brasileira das obras psicológicas completas de Sigmund Freud (Vol. 14, pp. 75-108). Rio de Janeiro: Imago.

Freud, S. (1996b). As pulsões e suas vicissitudes. In Edição standard brasileira das obras psicológicas completas de Sigmund Freud (Vol. 14). Rio de Janeiro: Imago. 
Freud, S. (1996c). Além do princípio do prazer. In Edição standard brasileira das obras psicológicas completas de Sigmund Freud (Vol. 18). Rio de Janeiro: I mago.

Freud, S. (1996d). Estudos sobre a Histeria. In Edição standard brasileira das obras psicológicas completas de Sigmund Freud (Vol. 2). Rio de Janeiro: I mago.

Freud, S. (1996e). Rascunho E: Como se origina a Angústia? In Edição standard brasileira das obras psicológicas completas de Sigmund Freud (Vol. 1). Rio de Janeiro: Imago.

Freud, S. (1996f). Notas psicanalíticas de um relato autobiográfico de um caso de paranoia. In Edição standard brasileira das obras psicológicas completas de Sigmund Freud (Vol. 12). Rio de Janeiro: I mago.

Freud, S. (1980). O ego e o id. In Edição standard brasileira das obras psicológicas completas de Sigmund Freud (Vol. 19). Rio de Janeiro: I mago.

Freud, S. (1986). A correspondência completa de S. Freud para W. Fliess. Rio de Janeiro: I mago.

Lacan, J. (2009). Lição sobre Lituraterra. In J. Lacan, Seminário, livro 18: de um discurso que não fosse semblante (pp. 105-119). Rio de Janeiro: J orge Zahar.

Lacan. J. (2008). A pulsão de morte. In J. Lacan, Seminário, livro 7: a ética na Psicanálise (pp. 246-260). Rio de Janeiro: Jorge Zahar.

Lacan, J. (2003). Radiofonia. In J. Lacan, Outros Escritos (pp. 400477). Rio de Janeiro: Jorge Zahar.

Lacan. J. (1998a). Introdução ao comentário de Jean Hyppolite sobre a "Verneinung" de Freud. In J. Lacan, Escritos (pp. 370-382). Rio de Janeiro: Zahar.

Lacan. J. (1998b). Seminário, livro 11: os quatro conceitos fundamentais da psicanálise. Rio de Janeiro: Jorge Zahar.

Lacan. J. (1998c). Posição do inconsciente. In J. Lacan, Escritos (pp. 843-864). Rio de Janeiro: Zahar.

Lacan, J. (1995). O seminário, livro 4: a relação de objeto (pp. 4058). Rio de Janeiro: J orge Zahar.

Lacan, J. (1985). O Seminário: Livro 20: mais, ainda (2a ed.). Rio de Janeiro: Jorge Zahar.

Lacet, C. (2003). Considerações sobre a letra e a escrita na clínica psicanalítica. Estilos da clínica - revista sobre a infância com problemas, 8(14), 50-59. Recuperado de http://pepsic. bvsalud.org/pdf/estic/v8n14/v8n14a05.pdf

Leite, M. P. (2000). Na segunda clínica de Lacan a palavra não se dirige ao Outro. Estilos da Clínica - revista sobre a infância com problemas, 5(9), 169-181. Recuperado de http://pepsic. bvsalud.org/pdf/estic/v5n9/_13.pdf 
Marty, P., \& M'Uzan, M. (1994). O pensamento operatório. Revista Brasileira de Psicanálise, 28(1), 165-174.

Masagão, A. M. (2008). A rasura da letra e a explosão do semblante. Ágora, 11(2), 313-331. doi: 10.1590/S151614982008000200010

Miller, J-A. (1986). La sustracción del sujeto. In J-A. Miller, Los signos del goce (pp. 27-38). Buenos Aires: Paidós.

Nicolau, R. F., \& Guerra, A. M. C. (2012). O fenômeno psicossomático no rastro da letra. Estudos e Pesquisas em Psicologia, 12(1), 226-241.

Recuperado

de http://pepsic. bvsalud.org/pdf/epp/v12n1/v12n1a13.pdf

Penna, L. M. D. M. (2003). Psicanálise, verdade e saber. In L. M. D. M. Penna, Psicanálise e Universidade: há transmissão sem clínica? (pp. 43-78). Belo Horizonte: Autêntica.

Queiroz, E. F. (2012). Dor e gozo: de Freud a Lacan. Revista Latinoamericana de Psicopatologia Fundamental, 15(4), 851867. doi: 10.1590/S1415-47142012000400008

Ramirez, H. H. A. E. (2004). Sobre a metáfora paterna e a foraclusão do nome-do-pai: uma introdução. Mental, 2(3), 89-105. Recuperado http://pepsic.bvsalud.org/pdf/mental/v2n3/v2n3a08.pdf

Rinaldi, D., Nicolau, R. F., \& Pitanga, C. E. G. D. A. (2013). Do fenômeno psicossomático ao sintoma: a aderência do sujeito ao diagnóstico médico e o trabalho analítico. Ágora: Estudos em Teoria Psicanalítica, 16(esp.), 95-108. doi:10.1590/S151614982013000300007

Santiago, J. (2001). A droga do toxicômano. Rio de Janeiro: Zahar.

Vidal, E. (2000). Uma letra que não se lê. Revista Letra Freudiana - A Prática da Letra, (26), 25-30. Recuperado de https: //pt. scribd.com/document/314672890/Revista-LetraFreudiana-Pratica-Da-Letra-N\% C2\% BA-26

Zucchi, M. (2014). Esse estranho que nos habita: o corpo nas neuroses clássicas e atuais. Opção lacaniana online, 14(5), 112.

Recuperado http://www.opcaolacaniana.com.br/pdf/numero_14/Esse_estra nho_que_nos_habita.pdf

\section{Endereço para correspondência J oão Pedro Gomes Previdello}

Rua Alameda Louveira, 616, Vivendas do Arvoredo, CEP 86055-784, Londrina - PR, Brasil

Endereço eletrônico: jp.previdello@gmail.com

I sadora Nicastro Salvador

Rua Delaine Negro, 55, apto 108, Bloco Rui Barbosa, Alto da Colina, CEP 86055680, Londrina - PR, Brasil

Endereço eletrônico: isadoranicastro94@gmail.com 


\section{Claudia Maria de Sousa Palma}

Rua Dr. Elias César, 55 sl 603, Ed. City Hall, Jardim Caiçaras, CEP 86015-640, Londrina - PR, Brasil

Endereço eletrônico: cacaupalma@gmail.com

Recebido em: 17/10/2018

Reformulado em: 11/03/2019

Aceito em: 09/04/2019

\section{Notas}

* Psicólogo graduado pela Universidade Estadual de Londrina, Pós-graduando em Especialização Fundamentos da Psicanálise.

** Psicóloga graduada pela Universidade Estadual de Londrina, Pós-graduanda no Programa de Mestrado em Psicologia da Universidade Estadual de Londrina.

*** Professora Adjunta do Departamento de Psicologia e Psicanálise - UEL. Doutora em Saúde Mental pelo Departamento de Psiquiatria e Psicologia Médica da FMRPUSP. Psicanalista.

Este artigo de revista Estudos e Pesquisas em Psicologia é licenciado sob uma Licença Creative Commons Atribuição-Não Comercial 3.0 Não Adaptada. 